\section{6 OPEN ACCESS}

\title{
Association of socioeconomic position with smoking and mortality: the contribution of early life circumstances in the 1946 birth cohort
}

\author{
Ingrid Giesinger, ${ }^{1}$ Peter Goldblatt, ${ }^{1}$ Philippa Howden-Chapman, ${ }^{2}$ Michael Marmot, ${ }^{1}$ \\ Diana Kuh, ${ }^{3}$ Eric Brunner ${ }^{1}$
}

\begin{abstract}
${ }^{1}$ Institute of Epidemiology and Health Care, University College London, London, UK ${ }^{2}$ New Zealand Centre for Sustainable Cities, University of Otago, Wellington, New Zealand

${ }^{3}$ MRC Unit for Lifelong Health and Ageing, London, UK

\section{Correspondence to} Ingrid Giesinger, Department of Epidemiology and Public Health, 1-19 Torrington Place, London, WC1E 6BT, UK: i.giesinger.11@alumni.ucl.ac. uk
\end{abstract}

Received 23 July 2013 Revised 14 October 2013 Accepted 17 October 2013 Published Online First 19 November 2013

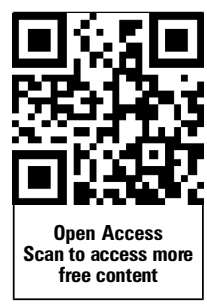

To cite: Giesinger I, Goldblatt P,

Howden-Chapman $\mathrm{P}$, et al. $J$ Epidemiol Community Health 2014;68:275-279.

\section{ABSTRACT}

Background A large part of the socioeconomic mortality gradient can be statistically accounted for by social patterning of adult health behaviours. However, this statistical explanation does not consider the early life origins of unhealthy behaviours and increased mortality risk.

Methods Analysis is based on 2132 members of the MRC National Survey of Health and Development with mortality follow-up and complete data. Smoking behaviour was summarised by pack-years of exposure. Socioeconomic circumstances were measured in childhood (father's social class (age 4), maternal education (age 6)) and age 26 (education attainment, home ownership, head of household social class). We estimated the direct effect of early circumstances, the indirect effect through smoking and the independent direct effect of smoking on inequality in all-cause mortality from age 26 to 66 .

Results Mortality risk was higher in those with lower socioeconomic position at age 26 , with a sex-adjusted HR (relative index of inequality) of 1.97 (95\% Cl 1.18 to 3.28). Smoking and early life socioeconomic indicators together explained $74 \%$ of the socioeconomic gradient in mortality (the gradient). Early life circumstances explained $47 \%$ of the gradient, $23.5 \%$ directly and $23.0 \%$ indirectly through smoking. The explanatory power of smoking behaviour for the gradient was reduced from $50.8 \%$ to $28 \%$ when early life circumstances were added to the model.

Conclusions Early life socioeconomic circumstances contributed importantly to social inequality in adult mortality. Our life-course model focusing on smoking provides evidence that social inequalities in health will persist unless prevention strategies tackle the intergenerational transmission of disadvantage and risk.

\section{INTRODUCTION}

Adverse behavioural factors such as smoking and poor diet tend to be more prevalent among individuals in lower socioeconomic positions (SEP). ${ }^{1-8}$ The extent to which such behaviours explain the persistent inverse social gradient in mortality is a fundamental health policy question. ${ }^{9}$ An analysis of mortality in the Whitehall II cohort that utilised repeated measures of key risk behaviours over 24 years of follow-up showed that a large part of the socioeconomic mortality gradient could be explained in this way. ${ }^{10}$ The analysis advanced the methodology by building a more realistic timedependent model of changing adult health behaviours and their health effects, thereby increasing substantially the explained proportion of the inequality in death rates compared with previous studies that were based only on the social pattern of behaviour at baseline. ${ }^{11-15}$

As the article and accompanying editorial noted, ${ }^{9}{ }^{10}$ socioeconomic inequalities in health are not reducible to health behaviours. The underlying reasons for the common social pattern in health behaviour-the causes of the causes-need to be investigated so that health inequities can be understood with a view to their reduction. ${ }^{16}$ The present analysis thus examines the childhood and early adult origins of the mortality gradient observed in the MRC National Survey of Health and Development (NSHD), ${ }^{17}{ }^{18}$ a British birth cohort study that has followed study members from birth, so far to age 66 years.

Previous studies have examined the childhood and adult origins of the mortality gradient at the same time in order to understand its causes and to provide evidence for preventive strategies within a life-course framework. ${ }^{19}{ }^{20}$ Starting in utero, each stage of life may contribute to individual levels of risk and to the social gradient in risk. The independent' effects of risk factor levels including SEP at different life-course stages or summed exposures across the life course have been estimated. ${ }^{17}{ }^{21-25}$ Other studies have gone beyond these conceptually cross-sectional approaches to estimate indirect as well as direct contributions of risk factors, thereby seeking to identify causal pathways, using techniques such as simultaneous multivariate and structural equation modelling. ${ }^{26} 27$ To our knowledge, ours is the first paper to focus on midlife smoking as the proximal mediating factor, quantifying both direct and indirect effects of early life-course circumstances on smoking pack-years and the social gradient in mortality between ages 26 and 66 .

\section{METHODS}

The NSHD's study design, population and sampling method have been described previously. ${ }^{28} 29$ Briefly, 5362 individuals born in England, Wales and Scotland during 1 week in March 1946 were enrolled in the study. Since 1971, 4461 study members have been flagged for death notification on the National Health Service Central Registry. ${ }^{28}$

Measures of early life origins were selected a priori based on Kuh et al. ${ }^{18}$ In childhood, they included maternal education and father's social class when study members were 4 years old, based on the Registrar General's Social Classification (RGSC). In early adulthood, they included study 
member educational attainment and home ownership by 26 years. ${ }^{18}$ Head of household's social class (RGSC at age 26) was derived from study member and spousal social class, and uses the class of the resident male in the house, if present, or female's class if not. The relative index of inequality (RII) based on RGSC age 26 was used in the Cox regression analysis of mortality.

Data for smoking over the life course, up to maximum age 64 , were collected at successive sweeps of the cohort and summarised in pack-years. ${ }^{30} \mathrm{~A}$ pack-year is equal to smoking one pack of 20 cigarettes each day for 1 year. Age of initiation was set at the mean (age 16) for those with missing data. The association between early life origins and smoking cessation by age 36 was explored through logistic regression. Among individuals with a history of smoking, ex-smokers were compared with current smokers to determine the odds of continued smoking at age 36 .

Cox's proportional hazards regression was used to study the relationship between life-course SEP and mortality, mediated by smoking behaviour (pack-years). Failure event was set as mortality; entry into the study was set to month 312 (age 26) and follow-up was until death, emigration or month 800 (age 66). The sex-adjusted HR for mortality based on the RII constituted the base model that was further adjusted for individual and combined covariates as follows (those with missing covariates were excluded):

- Base model: RII (age 26) +sex

- Model A: Base+early childhood SEP indicators

- Model B: Base+early adult SEP indicators

- Model C: Base+pack-years smoked

- Model D: Base+early childhood and early adult SEP indicators

- Model E: Base+early childhood and early adult SEP indicators+ pack-years smoked

The percentage reduction in the coefficient for RII was used to calculate the mediation proportion (attenuation) for each adjustment using the formula

$$
\left(\beta_{\text {RII-base }}-\beta_{\text {RII-model }}\right) /\left(\beta_{\text {RII-base }}\right) \times 100 \% \text {. }
$$

The bootstrap method with 2000 re-samplings was used to calculate 95\% CIs for the table 3 attenuation models.

\section{RESULTS}

Of the 5362 study members, 2132 were eligible for analysis after excluding observations with missing covariates $(n=2508$, smoking pack-years was the single largest contributor; $n=943$ ) or death, emigration or study withdrawal prior to age 26 $(n=722)$. Those excluded were compared with those included in the analysis. There were at most small differences in sociodemographic and behavioural variables between the two groups (data not shown).

Childhood circumstances predicted adult smoking habits at age 36 (table 1): individuals with fathers in a manual social class had higher odds of continued smoking compared with nonmanual. Those whose mothers had only primary education were more likely to continue smoking compared with those whose mothers had secondary level education. Smoking increased the mortality risk by $2 \%$ per pack-year smoked (table 2 ). Compared with those owning/buying their home at age 26, those who rented had an increased mortality risk.

The separate contribution of each covariate to the social gradient in mortality was estimated using the RII for RGSC at age
Table 1 ORs for continued smoking by age 36 for indicators of childhood socioeconomic position (age 4) obtained by logistic regression (current smoker vs ex-smoker and never smoker), 1768 study members

OR, sex adjusted $(95 \% \mathrm{Cl})$

$\begin{array}{ll}\text { Father's social class } & \\ \text { Non-manual } & 1 \\ \text { Manual } & 1.61 \text { (1.32 to } 1.95) \\ \text { Father's education } & \\ \text { Secondary level } & 1 \\ \text { Primary only } & 1.25 \text { (1.01 to } 1.53) \\ \text { Mother's education } & \\ \text { Secondary level } & 1 \\ \text { Primary only } & 1.62(1.29 \text { to } 2.03)\end{array}$

26 (table 2). Smoking (pack-years) accounted for 51\% of the social gradient in mortality in the cohort based on social class at age 26 .

\section{Direct and indirect pathways to mortality}

Childhood and early adult SEP indicators were added to the base model by life stage (table 3 ). Early childhood indicators combined (model A) accounted for $18 \%$ of the mortality gradient. Early adult indicators (model B) accounted for about double the proportion (35\%) of the mortality gradient. The combination of early childhood and early adult indicators attenuated the mortality gradient by $47 \%$ (model D), a proportion approaching that attributable to smoking (51\%, model C). Considering smoking history together with early life origins in the full model (model E), the proportion of the gradient explained is $74 \%$.

The attenuating effects in models $\mathrm{C}, \mathrm{D}$ and $\mathrm{E}$ were decomposed to quantify the life-course pathway model (figure 1 ). The direct smoking effect ( $28 \%$ of inequality in mortality explained) is derived from the difference between the full model $\mathrm{E}(74 \%$ explained) and the early life-course model D, which omits smoking (47\% explained). Comparing model $\mathrm{C}$ with the direct smoking effect provides the indirect effect of early life mediated by smoking (51-28\%). To account for the direct effect of early life origins, the indirect effect through smoking is taken from the total early life effect (23.5\% explained).

\section{DISCUSSION}

This study highlights the major role of early life circumstances as causes of inequalities in health. It emphasises how important it is, in the context of the policy debate, to recognise the intergenerational transmission of risk and the accumulation of disadvantages that can occur during childhood. ${ }^{31}$ First, the combination of material and psychosocial conditions in childhood was almost as powerful as smoking in accounting for the inequality in adult mortality experienced in this cohort. Second, the effects of early life circumstances were seen to extend far into adult life and to influence mortality risk by shaping continued exposure to smoking and by implication other risk behaviours that were omitted so as to facilitate analytic clarity. Smoking history was in substantial part attributable to early life circumstances, characterised by father's occupational class and mother's level of education.

There is considerable evidence for the operation of pathways that connect early life disadvantage with poor health and 
Table 2 HRs for risk factors and effect of adjustment for single risk factors on the relative index of inequality for mortality by head of household social class at age 26 obtained using Cox's proportional hazards regression

\begin{tabular}{|c|c|c|c|}
\hline \multirow[b]{2}{*}{ Adjustment variables } & \multicolumn{3}{|l|}{ All-cause mortality } \\
\hline & HR for risk factor, sex adjusted ( $95 \% \mathrm{Cl})$ & Relative index of inequality $(95 \% \mathrm{Cl})$ & $\%$ Change in relative index of inequality \\
\hline Sex (base model) & 0.84 (0.64 to 1.12$)$ & 1.97 (1.18 to 3.28$)$ & Baseline \\
\hline \multicolumn{4}{|l|}{ Early life indicators (age 4) } \\
\hline Father's social class & $1.09(0.80$ to 1.50$)$ & 1.86 (1.08 to 3.21$)$ & -8.3 \\
\hline Mother's education & 1.30 (0.87 to 1.94$)$ & 1.77 (1.04 to 3.02$)$ & -15.8 \\
\hline \multicolumn{4}{|l|}{ Early adulthood indicators (age 26) } \\
\hline Educational qualifications & 1.20 (0.88 to 1.64$)$ & 1.71 (0.97 to 3.01$)$ & -21.2 \\
\hline Home ownership & 1.44 (1.08 to 1.94$)$ & 1.74 (1.04 to 2.93$)$ & -18 \\
\hline Cigarette smoking (pack-years) & $1.02(1.02$ to 1.03$)$ & 1.40 (0.82 to 2.37$)$ & -50.8 \\
\hline
\end{tabular}

increased mortality risk in adulthood. ${ }^{32}$ These pathways involve combinations of early exposure to socioeconomic, behavioural and biological factors that affect adult mortality risk in ways specific to age, place of residence and calendar time. There may be critical events, such as poor in utero growth leading to low birth weight ${ }^{33}$; accumulation of risk, such as that due to constrained upward social mobility ${ }^{24}$; chains of risk involving a sequence of adverse exposures, such as may be initiated by poor housing conditions in childhood; ${ }^{34}$ or a complex interaction between these pathways, that lead to an increase in adult mortality risk.

Both childhood and adult socioeconomic circumstances have been shown to influence adult smoking behaviour. Lower childhood SEP is associated with an increased risk of smoking initiation, progression to regular smoking and a reduced likelihood of cessation. Similar results were found when analysis used adult SEP. $^{35}$ Manual social class in childhood decreased the likelihood of adult smoking cessation. ${ }^{6}$ Current smoking (vs never and ex-smoking), after adjusting for adult social class in some populations, is associated with childhood social class in women. ${ }^{6}$ Childhood social class and nicotine dependence both influence adult smoking behaviour. ${ }^{4}$

Our analysis shows empirically that an explanation of health inequality wholly reliant on adult health behaviours is incomplete. Time-dependent analysis of changing risk behaviours raises the proportion of inequality explainable by more

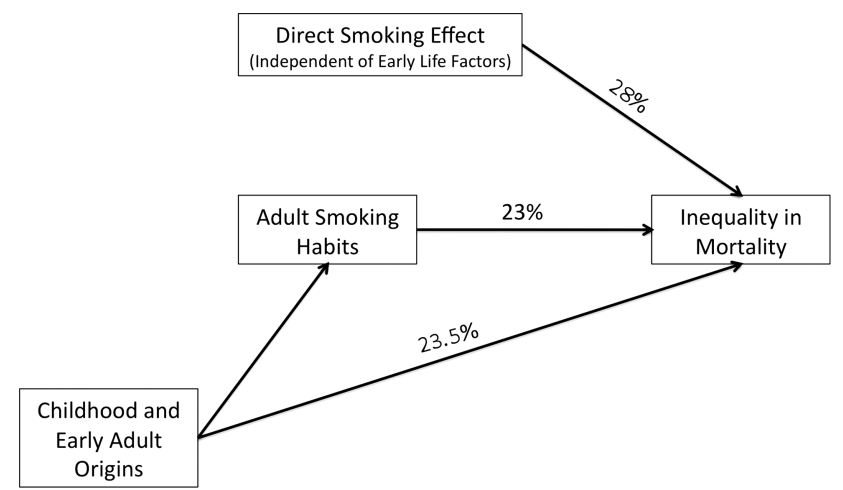

Figure 1 Life-course pathway from early life origins to inequality in mortality mediated by smoking. Figures are percentage of inequality in mortality accounted for in the cohort. Adult smoking habits account for $51 \%$ of inequality in mortality, of which $45 \%(23 \% / 51 \%)$ is attributable to childhood and early adult origins. accurately specifying exposure. ${ }^{10}$ We have extended this logic by extending the time at risk back to early childhood to include some of the 'causes of the causes'-in this case, the inequalities in early socioeconomic and cultural advantage that produce the social gradient in mortality, in part through their influence on patterns of adult health behaviours. A key finding is that markers of early life increase the explanatory power of the model for the mortality gradient by approaching 50\% over the substantial proportion explained by smoking behaviour on its own.

Our model utilises pack-years as the measure of life-course exposure to tobacco smoke. In consequence, the analysis does not account for passive exposure. The summary pack-years measure further relies on some assumptions. Among these, it is assumed that reporting bias concerning smoking status is similar by social class across rounds of data collection and that the social gradients in age at initiation and cessation do not distort the findings from the analytical models. The social gradient in smoking cessation in the NSHD is greater than the gradient in smoking uptake. ${ }^{6} 36$ Thus, the same level of exposure based on the pack-years measure may represent a somewhat different health effect across social strata.

As indicated above, the statistical model for the mortality gradient focuses on the intermediate role of smoking. Other health behaviours, environmental exposures and biological factors have been omitted. If the model included additional adult health behaviours such as dietary pattern, the independent effect of early life would likely diminish because the model would more fully represent the causal relationships that link childhood deprivation to adult health behaviours and social disparities in adult mortality. ${ }^{7} 37$ The association of manual father's social class with mortality was not significant in this analysis. In contrast, there was an inverse association in the cohort when participants with missing data were included in the Cox model as a separate group. ${ }^{30}$ If the effect of early life has been underestimated in the present analysis, it may be that the estimate of the explanatory power of early life circumstances is also biased downwards.

The extent of inequality in mortality is similar in Great Britain and France, but smoking and other social patterns of health behaviour account for much less of the social gradient in France. ${ }^{38}$ Whatever other adult risk factors underlie the health inequalities, the primary cause in France is likely to be found in the social patterning of childhood advantage, as in Great Britain. Effective policy to reduce health inequality in different societies may therefore depend on population-specific variations 
Table 3 Effect of adjustment for early childhood and early adult socioeconomic indicators and health behaviours on the relative index of inequality (head of household social class at age 26) for mortality

\begin{tabular}{|c|c|c|}
\hline & \multicolumn{2}{|l|}{ All-cause mortality } \\
\hline & $\begin{array}{l}\text { Adjusted relative index } \\
\text { of inequality }(95 \% \mathrm{CI})\end{array}$ & $\begin{array}{l}\% \text { Change in relative index } \\
\text { of inequality }(95 \% \mathrm{Cl})\end{array}$ \\
\hline \multicolumn{3}{|l|}{ Adjustments } \\
\hline Sex (base model) & 1.97 (1.18 to 3.28$)$ & Baseline \\
\hline \multicolumn{3}{|l|}{ Early childhood variables } \\
\hline Sex+father's social class+mother's education (model A) & 1.74 (1.00 to 3.04$)$ & $-18.1(-88$ to 17$)$ \\
\hline \multicolumn{3}{|l|}{ Early adult variables } \\
\hline Sex+highest educational attainment+home ownership (model B) & 1.54 (0.87 to 2.75$)$ & $-35.8(-229$ to 0.5$)$ \\
\hline \multicolumn{3}{|l|}{ Cigarette smoking } \\
\hline Sex+pack years smoked (model C) & 1.40 (0.82 to 2.37$)$ & $-50.8(-188$ to -23$)$ \\
\hline \multicolumn{3}{|l|}{ Early life-course variables } \\
\hline Sex+early childhood+early adult variables (model D) & 1.44 (0.79 to 2.62 ) & $-46.5(-181$ to 1.5$)$ \\
\hline \multicolumn{3}{|l|}{ Early life-course and smoking behaviour } \\
\hline Sex+early childhood+early adult variables+smoking (model E) & $1.19(0.65$ to 2.18$)$ & $-74.3(-251$ to -20$)$ \\
\hline
\end{tabular}

in measures along with similar life-course perspectives on the causes of health inequalities. $^{30} 39$

\section{What is already known on this subject}

- Beliefs about the causes of social inequalities in health are central to the debate about what the appropriate policy response should be.

- Adult health behaviours provide a largely complete statistical explanation for inequalities in mortality when the analytical model incorporates time-varying measures of exposure.

- In the Whitehall II study, $72 \%$ of the social gradient in all-cause mortality could be explained by smoking behaviour, alcohol consumption, dietary indicators and physical activity, allowing for their variation over 24 years of follow-up.

\section{What this study adds}

- Differences in childhood and early adult circumstances are the underlying causes of social inequalities in both adult health behaviours and mortality.

- Policies focused only on adult health behaviours do not address the socially patterned causes of these behaviours or the independent role played by these causes in social inequalities in health.

Contributors IG, PG, DK, EB, PH-C and MM made substantial contributions to the conception and design, acquisition of data, or analysis and interpretation of data; and the final approval of the version to be published. IG, PG, DK and EB were responsible for drafting the article or revising it critically for important intellectual content.
Funding Professor Brunner is supported by the British Heart Foundation. Professor Kuh, and the MRC National Survey of Health and Development is supported by the UK Medical Research Council (MC_UU_12019/01).

Competing interests None.

Ethics approval The study received Multi-Centre Research Ethics Committee approval, and informed consent was given by cohort participants.

Provenance and peer review Not commissioned; externally peer reviewed.

Open Access This is an Open Access article distributed in accordance with the Creative Commons Attribution Non Commercial (CC BY-NC 3.0) license, which permits others to distribute, remix, adapt, build upon this work non-commercially, and license their derivative works on different terms, provided the original work is properly cited and the use is non-commercial. See: http://creativecommons.org/ licenses/by-nc/3.0/

\section{REFERENCES}

1 Laaka TA, Kauhanen J, Salonen J. Conditioning leisure time physical activity and cardio respiratory fitness in socio-demographic groups of middle-aged men in Eastern Finland. Int J Epidemiol 1996:25:86-93.

2 Gilman S, Abrams D, Buka S. Socioeconomic status over the life course and cigarette use: initiation, regular use and cessation. J Epidemiol Community Health 2003; $57: 802-8$

3 Martikainen $P$, Brunner $E$, Marmot M. Socioeconomic differences in dietary patterns among middle-aged men and women. Soc Sci Med 2003;56:1397-410.

4 Jefferies B, Graham H, Manor O, et al. Cigarette consumption and socio-economic circumstances in adolescence as predictors of adult smoking. Addiction 2003;98:1765-72.

5 Jefferies B, Power C, Graham $\mathrm{H}$, et al. Changing social gradients in cigarette smoking and cessation over two decades of adult follow-up in a British birth cohort. J Public Health 2004;26:13-8.

6 Power C, Graham H, Due P, et al. The contribution of childhood and adult socioeconomic position to adult obesity and smoking behaviour: an international comparison. Int J Epidemiol 2005:34:335-44.

7 Lynch J, Kaplan G, Salonen J. Why do poor people behave poorly? Variation in adult health behaviours and psychosocial characteristics by stages of the socioeconomic lifecourse. Soc Sci Med 1997;44:809-19.

8 Osler M, Godtfredsen N, Prescott E. Childhood social circumstances and health behavior in midlife: the Metropolit 1953 Danish male birth cohort. Int J Epidemiol 2008:37:1367-74.

9 Dunn J. Health behaviour vs the stress of low socioeconomic status and health outcomes. JAMA 2010;303:1199-200.

10 Stringhini $S$, Severine $S$, Shipley $M$, et al. Association of socioeconomic position with health behaviors and mortality. JAMA 2010;303:1159-66.

11 Marmot M, Shipley M, Rose G. Inequalities in death-specific explanations of a general pattern? Lancet 1984;323:1003-6.

12 Lantz P, House J, Lepkowski J, et al. Socioeconomic factors, health behaviours, and mortality: results from a nationally representative prospective study of US adults. JAMA 1998:279:1703-8. 
13 Woodward M, Oliphant J, Lower G, et al. Contribution of contemporaneous risk factors to social inequality in coronary heart disease and all-cause mortality. Prev Med 2003;36:531-68.

14 Strand B, Tverdal A. Can cardiovascular risk factors and lifestyle explain the educational inequalities in mortality from ischemic heart disease and from other diseases? J Epidemiol Community Health 2004;58:705-9.

15 Laaksonen M, Talala K, Martelin T, et al. Health behaviours as explanations for educational level differences in cardiovascular and all-cause mortality. Eur J Public Health 2008; 18:38-43.

$16 \mathrm{CSDH}$. Closing the gap in a generation: health equity through action on the social determinants of health. Final Report of the Commission on Social Determinants of Health. Geneva, World Health Organization, 2008.

17 Kuh D, Hardy R, Langenberg C, et al. Mortality in adults aged 26-54 years related to socioeconomic conditions in childhood and adulthood: post war birth cohort study. BMJ 2002;325:1076-80.

18 Kuh D, Shah I, Richards M, et al. Do childhood cognitive ability or smoking behaviour explain the influence of lifetime socio-economic conditions on premature adult mortality in a British post war birth cohort? Soc Sci Med 2009;68:1565-73.

19 Blane D. The life course, the social gradient, and health. In: Marmot M, Wilkinson RG, eds. Social determinants of health. 2nd edn. Oxford: Oxford University Press, 2006:54-77.

20 Galobardes B, Lynch JW, Smith GD. Is the association between childhood socioeconomic circumstances and cause-specific mortality established? Update of a systematic review. J Epidemiol Community Health 2008;62:387-90.

21 Blane D, Hart CL, Smith GD, et al. Association of cardiovascular disease risk factors with socioeconomic position during childhood and during adulthood. BMJ 1996;13:1434-8

22 Davey Smith G, Hart C, Blane D, et al. Adverse socioeconomic conditions in childhood and cause specific adult mortality: prospective observational study. BMJ 1998:316:1631-35

23 Brunner E, Shipley MJ, Blane D, et al. When does cardiovascular risk start? Past and present socioeconomic circumstances and risk factors in adulthood. J Epidemiol Community Health 1999;53:757-64.

24 Power C, Manor O, Matthews S. The duration and timing of exposure: effects of socioeconomic environment on adult health. Am J Public Health 1999;89:1059-65.

25 Naess $\varnothing$. Claussen B, Thelle DS, et al. Cumulative deprivation and cause specific mortality. A census based study of life course influences over three decades. J Epidemiol Community Health 2004;58:599-603.
26 Van Oort FV, van Lenthe FH, Mackenbach JP. Material, psychosocial, and behavioural factors in the explanation of educational inequalities in mortality in The Netherlands. J Epidemiol Community Health 2005:59:214-20.

27 Chandola T, Clarke P, Morris JN, et al. Pathways between education and health: a causal modelling approach. J $R$ Statis Soc A 2006;169:337-59.

28 Kuh D, Pierce M, Adams J, et al. Updating the cohort profile for the MRC National Survey of Health and Development: a new clinic-based data collection for ageing research. Int J Epidemio/ 2011;40:e1-9.

29 Wadsworth M, Kuh D, Richards M, et al. Cohort Profile: the 1946 national birth cohort (MRC National Survey of Health and Development). Int J Epidemiol 2006;35:49-54

30 Strand B, Mishra G, Guralnik J, et al. Smoking history and physical performance in midlife: results from the British 1946 birth cohort. J Gerontol A Blol Sci Med Sci 2011;66:142-9.

31 Power C. Social and economic background and class inequalities in health among young adults. Soc Sci Med 1991:32:411-17.

32 Kuh $D$, Power $C$, Blane $D$, et al. Socioeconomic pathways between childhood and adult health. In: Kuh D, Ben Shlomo Y, eds. A life course approach to chronic disease epidemiology. 2nd edn. Oxford: Oxford University Press, 2004;370-96.

33 Bartley M, Power C, Blane D, et al. Birth weight and later socioeconomic disadvantage: evidence from the 1958 British cohort study. BMJ 1994;309: 1475-8.

34 Mann SL, Wadsworth MEJ, Colley JRT. Accumulation of factors influencing respiratory illness in members of a national birth cohort and their offspring J Epidemiol Community Health 1992;36:286-92.

35 Gilman SE, Abrams DB, Buka SL. Socioeconomic status over the life course and stages of cigarette use: initiation, regular use, and cessation. J Epidemiol Community Health 2003;57:802-8.

36 Pugh H, Power C, Goldblatt P, et al. Women's lung cancer mortality, socio-economic status and changing smoking patterns. Soc Sci Med 1991;32:1105-10.

37 Brunner EJ, Mosdol A, Witte DR, et al. Patterns and 15-y risks of major coronary events, diabetes, and mortality. Am J Clin Nutr 2008;87:1414-21.

38 Stringhini S, Dugravot A, Shipley $M$, et al. Health behaviours, socioeconomic status, and mortality: further analysis of the British Whitehall II and the French GAZEL prospective cohorts. PLoS Med 2011;8:e1000419.

39 Marmot M. Fair society, healthy lives: the Marmot Review : strategic review of health inequalities in England post-2010. The Marmot Review. 2010. 